\title{
Trabalho infantil e produção acadêmica nos anos 90: tópicos para reflexão
}

\author{
Marcos Artemio Fischborn Ferreira \\ Universidade de Santa Cruz do Sul
}

\begin{abstract}
Resumo
O texto tem por objetivo discutir algumas relações entre a institucionalização das ações contra a exploração do trabalho infantil e produção acadêmica nos anos noventa no Brasil. São recuperados alguns elementos dos cenários nacional e internacional que determinaram a visibilidade do tema na forma de um fenômeno social relevante e inaceitável. No caso brasileiro, foi fundamental a combinação entre a consolidação de um pacto democrático materializado na definição constitucional de direitos, a constituição de uma rede institucional de apoio e proteção à infância e adolescência sob influência dos discursos internacionais e a abertura de linhas de investigação que concorrem para o desvendamento de aspectos ainda pouco conhecidos da realidade sócio-econômica, entre elas o trabalho precoce. Preconiza-se a renovação das abordagens em pesquisa, desenhando projetos que tenham como objeto a preocupação de refinar o conhecimento sobre determinantes e impactos do trabalho precoce, onde a cooperação entre campos disciplinares é altamente desejável, dada a complexidade do fenômeno.
\end{abstract}

Palavras-chave: Trabalho infantil, Trabalho precoce, Direitos da criança, Trabalho e saúde.

\begin{abstract}
Child labor and academic research: Reflections about a walk in the nineties. The aim of this paper is to discuss some relations between academic research and the ascending and institutionalized movement against child labor exploitation in Brazil in the nineties. The interweaving between a democratic scenery consolidation through the new Brazilian Federal Constitution, an ascending institutional youth and infancy supporting net influenced by international discourses, and the opening of academic research lines facing the "new" identified object of child labor, are seen as fundamental to change aspects of the reality. Its necessary to renew the research approaches to know better, with finer analytical instruments and the cooperation between disciplinary fields, the whole complexity of this object in order to subsidize more consistent intervention on reality.
\end{abstract}

Key words: Child labor, Children Rights, Child labor research

$\mathrm{E}$ sta comunicação compreende uma tentativa de explorar algumas relações entre produção acadêmica e estratégias de prevenção e erradicação do trabalho infantil nos anos noventa, particularmente no Brasil. O desenvolvimento do trabalho tem por base as análises e resultados de pesquisas coordenadas pelo autor, consultorias e teses orientadas nos últimos anos sobre o tema. Esta experiência é complementada por informações captadas em duas das principais bases sobre trabalho infantil do país, o Prossiga do CNPq e da Fundação ABRINQ, além de páginas institucionais na Internet.
Um dos argumentos que balizam a discussão é de que o conhecimento dos aspectos genéricos sobre o trabalho infantil ou precoce ${ }^{1}$ teve um papel importante no desencadeamento de ações do governo e sociedade no seu combate e prevenção nesta década, mas, seu vigor dá mostras de insuficiência para as tarefas a realizar. Como argumento central levanto que os estudos amplos e genéricos cumpriram seu objetivo de desvendar uma realidade detestável, plena de riscos e vulnerabilidades, mas parecem estar esgotando sua missão. O exame de variáveis sócio-econômicas e demográficas em levantamentos exaustivos, ou nem tanto, promoveu o esclare- 
cimento de uma realidade que teimava em permanecer silenciosa, sinalizando alguns caminhos para mudança. No entanto, as estratégias de combate têm padecido de lacunas importantes de conhecimento nos vários lugares onde o trabalho infantil se apresenta, impedindo que as iniciativas sejam mais qualificadas e alcancem maior eficácia tanto na eliminação quanto na estruturação de estratégias preventivas. Em conseqüência, levanto a necessidade de multiplicar estudos com recortes mais específicos, seja em relação à delimitação espacial, como na configuração interior dos mais diversos campos disciplinares e/ou em objetos que os trespassem, nummovimento de cooperação entre disciplinas/áreas do conhecimento.

O trabalho precoce apresenta-se como um fenômeno social importante pelas características de que foi revestido: envolver crianças, a maioria pobre, sem oportunidades efetivas de crescimento e desenvolvimento, não raro (mas longe de ser exclusivo) em áreas/regiões com estagnação econômica importante, fatores potencializados pela inatividade do poder público e baixa sensibilidade social, tornando-as junto com suas famílias - indivíduos submetidos a um estado de vulnerabilidade inaceitável para os padrões de uma sociedade que se deseja próspera e democrática.

Sociedade e governo mobilizaram uma ampla articulação entre produção científica, decisões políticas, legais e administrativas em relação ao tema, com todas as limitações que uma dinâmica desse tipo possa apresentar, inclusive a de produzir impactos sensíveis na transformação da realidade em foco, levando-se em conta a complexidade que o fenômeno apresenta. Com exceção da campanha contra a fome liderada por Betinho, não lembro de outro chamado que tenha alcançado tamanho sucesso na mobilização de setores de governo das três esferas administrativas, entidades nãogovernamentais, organizações sindicais, associações profissionais, comissões parlamentares, setores corporativos empresariais, eclesiásticos, artísticos, partidos políticos e universidades, pelo menos no que diz respeito à adesão de primeiro momento. Todos, com raríssimas exceções, empenharamse em assinalar/demonstrar seu repúdio e a necessidade de desencadear esforços para mudar definitivamente a realidade do trabalho na infância e adolescência.

A análise de alguns aspectos mais centrais dos significados promovidos pelo movimento de combate ao trabalho infantil e seus resultados deve, necessariamente, passar pelo exame da dinâmica imprimida pelos atores mais envolvidos no empreendimento, assim como dos componentes que agenciaram a fisionomia da nova realidade - caso ela tenha efetivamente se tornado "nova" diante da siniciativas levadas a efeito ${ }^{2}$.

\section{A cena internacional}

Qualquer exame mais apurado sobre o assunto obriga a localizar na Organização Internacional do Trabalho o espaço institucional mais sensível e dinamizador na difusão de conhecimento e articulação de iniciativas sobre o trabalho precoce no mundo inteiro. A organização dedica um setor inteiro de sua máquina administrativa para manter-se informada, elaborar estatísticas, promover a difusão das experiências mais notáveis de combate ao trabalho precoce, disseminar metodologias de trabalho, incentivar e coordenar programas, expor sua posição institucional e estatuir os marcos legais sobre o tema. A partir dela é que nos anos noventa o trabalho precoce alcançou o estatuto de "problema social relevante" nos quatro cantos do mundo, quando governos e sociedades foram desafiados a "perceber que essa era uma realidade inaceitável, e, em decorrência, sensibilizar-se para o fato e agir". (OIT, 1993)

Já em 1919 a agência formulava uma medida voltada para limitar em 14 anos a idade limite para contratação de jovens pela indústria. "Le siguieron otros convenios prohibiendo trabajo infantil en el mar, la pesca, la agricultura, las empresas industriales y las minas" (OIT, 1993, p. 4).

Ao longo do século vinte foram várias as medidas divulgadas pela Organização, voltando seus esforços para ampliar progressivamente o espectro de atividades laborais a serem reguladas quanto ao aspecto de idade mínima de ingresso e quanto às restrições a serem observadas em relação ao trabalho dos jovens. No total foram 17 normas entre convenções e recomendações.

O caráter das medidas que vão se sucedendo revela-se contido na medida em que se traduz por uma postura apenas "limitante" e reguladora de alguns aspectos desse trabalho, num cenário onde o uso e abuso da força de trabalho infantil eram tratados como um fato "natural" da economia. Ilustrativo é o texto da Convenção 60, de 1937, voltada para a idade mínima no trabalho não-industrial. Nela, o empenho volta-se para reduzir progressivamente o espaço de inserção de crianças no trabalho, além da indústria, mas desde que

no child under 14 years of age shall be employed on light work for more than two hours per day whether that day be a school day or a holiday, and spend at school and on light work a total number of hours exceeding seven per day (ILO, 1997, II 23).

Os avanços efetivos, pelo menos do ponto de vista discursivo expresso nos acordos internacionais, aparecem já em 1959 na Declaração dos Direitos da Criança, proclamada na Assembléia Geral das Nações Unidas. Em seu princípio de número 9, preconiza que

The child shall be protected against all forms of neglect, cruelty and exploitation. He shall not be the subject of traffic, in any form.

The child shall not be admitted to employment before an appropriate minimum age; he shall in no case be caused or permitted to engage in any occupation or employment which would prejudice his health or education, or inter- 
fere with his physical, mental or moral development (UN, 2000).

Em 1973, a OIT formula a Convenção 138 que seus documentos mais recentes definem como "a base de toda a política da OIT sobre a eliminação gradual do trabalho infantil e proteção contra as condições adversas que o agravam" (OIT, 1987, p. 6). Esta aponta para a necessidade dos países membros formularem políticas para a idade mínima vinculando-as à escolaridade compulsória, tratando do tema sob a perspectiva da preservação da saúde e desenvolvimento dacriança.

A visibilidade alcançada pelo significado do trabalho precoce apoiou-se nos novos conceitos de infância e adolescência, seus direitos, limites psíquicos e físicos para a realização de determinadas atividades e o impacto que produzem em sua trajetória de vida.

A realidade internacional, após uma década de recessão para muitos países do terceiro mundo, apresentava um cenário desolador para a infância exigindo atitudes de impacto por parte de governos e agências internacionais com relação à infância, que teve na Convenção dos Direitos da Criança de 1989,

Profoundly concerned that the situation of children in many parts of the world remains critical as a result of inadequate social conditions, natural disasters, armed conflicts, exploitation, illiteracy, hunger and disability, and convinced that urgent and effective national and international action is called for... Adopts and opens for signature, ratification and accession the Convention on the Rights of the Child contained in the annex to the present resolution (UN, 1989).

Estudos e experiências dispersos subsidiaram as decisões que os organismos internacionais e organizações nãogovernamentais adotaram em seus discursos a respeito do que seria doravante considerado correto a definir as medidas para proteção da infância,

Creating an important place for children's rights on the world's agenda by being the most widely ratified treaty in the world. Adopted by the United Nations General Assembly on November 20, 1989, the Convention promises children around the world the right to life, liberty, education, and health care. It provides protection to children in armed conflict, protection from discrimination, protection from torture or cruel, inhuman or degrading treatment or punishment, protection within the justice system, and protection from economic exploitation, in addition to many other fundamental protections (HRW, 2001).

A Convenção para os Direitos da Criança de 1989 buscou sensibilizar os setores responsáveis do mundo inteiro para uma pauta extensa de questões sobre a infância, todas interligadas, apontando a urgência do tratamento da maioria delas sob a ótica da integralidade de ações, onde a noção de intersetorialidade toma vulto. Em seu artigo 32 a Convenção formula que:

1. States Parties recognize the right of the child to be protected from economic exploitation and from performing any work that is likely to be hazardous or to interfere with the child's education, or to be harmful to the child's health or physical, mental, spiritual, moral or social development.

2. States Parties shall take legislative, administrative, social and educational measures to ensure the implementation of the present article. To this end, and having regard to the relevant provisions of other international instruments, States Parties shall in particular:

(a) Provide for a minimum age or minimum ages for admission to employment;

(b) Provide for appropriate regulation of the hours and conditions of employment;

(c) Provide for appropriate penalties or other sanctions to ensure the, effective enforcement of the present article (UN, 1989).

Na abordagem observa-se um deslocamento do sentido que toma o ato de uma criança trabalhar, desde uma visão que tinha como base as necessidades da economia em contar com essa força de trabalho, tratando-a um fator "natural" de produção, para uma outra concepção, onde a ênfase recai sobre as especificidades que configuram a infância como um período ímpar do ciclo vital. Esse é um movimento de grande alcance qualitativo na medida em que passa operar sob um ponto de vista teórico-conceitual que toma o significado de ser criança como uma centralidade, considerando toda interferência indevida na vida da criança, todo fato que atente contra seu desenvolvimento, como violação de direitos. Em decorrência, a recomendação é de que os diagnósticos sejam child centered, ou seja, interessa antes de tudo, o quanto a criança passa a ser afetada em suas circunstâncias de vida e necessidades em função da necessidade de trabalhar (Bequelle \& Myers, p. 1995).

\section{Repercussões brasileiras}

$\mathrm{O}$ fato mais marcante ocorrido no Brasil nessa era de reconhecimento crescente de direitos é o nascimento do Estatuto da Criança e do Adolescente (doravante, ECA), com a lei 8.069/90 substituindo o arcaico Código de Menores. Inspirado na Convenção dos Direitos da Criança de 1989, na Constituição de 1988 e em outras leis internacionais, passa a reger a totalidade dos assuntos referentes à infância e adolescência no país. A Constituição Federal de 1988 já promovera a fundamentação necessária para o nascimento de uma legislação mais avançada, principalmente através de seu 
Artigo 227 que deixava claro, "o dever da família, da sociedade e do Estado assegurar à criança e ao adolescente, com absoluta prioridade, o direito à vida, à saúde, à alimentação, à educação, ao lazer, à profissionalização, à cultura, à dignidade, ao respeito, à liberdade e à convivência familiar e comunitária, além de colocá-los a salvo de toda forma de negligência, discriminação, violência, crueldade e opressão". (Brasil, 1998).

Como decorrência das postulações do ECA, estruturouse, ao longo da década dos anos noventa, uma rede de instituições com papéis definidos em suas esferas específicas para atenção à infância e adolescência, como os Conselhos de direitos ${ }^{3}$ - Municipais, Estaduais e Nacional - e os Conselhos Tutelares. A assimilação das novas concepções pela sociedade e sua materialização em estruturas institucionais e o desenvolvimento de ações em vários campos que dizem respeito aos direitos de crianças e adolescentes são lentos e carecem de um período impossível de prever para sua maturação ${ }^{4}$. Os resíduos de uma longa história de atitudes autoritárias e disciplinadoras ainda persistem como obstáculos importantes para que a mudança discursiva se realize na prática cotidiana.

O deslizamento muito freqüente, de agentes sociais variados, para a preferência por ações repressivas impõe o exercício da vigilância permanente, mas essa não é uma dificuldade isolada. A ação institucional tem se mostrado frágil e com um nível de comprometimento muito baixo, se for levada em conta a complexidade dos fatos que cercam a violação dos direitos à infância. A começar pelos próprios locais de atendimento - muitos deles com fisionomias pouco amigáveis, em prédios e instalações precárias - e o pessoal envolvido na linha de frente do atendimento e dos processos decisórios, ainda persiste um grave menosprezo pela questão social, dando continuidade a uma tradição pouco recomendável $^{5}$. As violações de direitos são constantes no cotidiano das famílias em todos os cantos do país, onde se incluem os episódios vergonhosos das chacinas, rebeliões, entre tantos outros atos de violência, desenhando um quadro de horror e abandono. Esse painel institucional insatisfatório pode ser compreendido na moldura de uma sociedade que persiste com acentuado grau de desigualdades, onde os efeitos da exclusão se fazem sentir nas várias dimensões da vida das classes populares. A condição subalterna é uma condição de desvalia que determina ao mesmo tempo vulnerabilidade extrema e baixíssima capacidade de reação diante de situações objetivas como a de não ter onde morar (e viver em áreas de risco), dificuldades para alimentar-se, falta de acesso a bens culturais ou não contar com serviços públicos que compensem minimamente as adversidades geradas no mercado.

Malgrado essas dificuldades em vários planos da aplicação das políticas e das vicissitudes da vida social em seu todo, a década de noventa foi cenário de movimentação intensa na área da infância e adolescência. Pelo menos o movimento de renovação discursiva produziu algum equilíbrio no debate, que pendia sensivelmente para as posições conservadoras e repressivas.

Cabe salientar também que uma das instituições a exercer um papel relevante junto às questões de infância e adolescência, foram os Ministérios Públicos, cuja missão institucional foi ampliada após 1988. As chamadas Defensorias têm desenvolvido papel importante tanto no que se refere à abertura de processos de investigação através de denúncias, na defesa de direitos difusos e desencadeamento de ações repressivas, como na divulgação de conhecimentos dos diversos aspectos legais sobre direitos e as consequiências de sua violação.

A malha institucional e legal, nascida e desenvolvida gradualmente no período, foi terreno fértil para acolher os propósitos de combate ao trabalho precoce, trazendo à tona mais uma das tantas faces da exploração econômica no país.

Ações sobre o trabalho infantil e a emergência de um novo objeto

A OIT, o UNICEF, o Governo Federal, através do Gabinete da Presidência da República e do Ministério do Trabalho (e, mais recentemente, "do Trabalho e Emprego"), a Comissão Mista do Congresso de Combate ao Trabalho Infantil, e setores da sociedade civil como a Fundação ABRINQ e da Igreja Católica compõem alguns dos principais loci desencadeadores de produção documental, articulação política, formação de opinião, formulação de estratégias e realização de ações concretas. Esse painel considerável de atores, com a atenção concentrada sobre o mesmo tema, delineou a importância social que representava o trabalho infantil, na medida que apontava para a exigência da congregação de esforços institucionais, num movimento colaborativo cuja abrangência permitisse desencadear ações em vários níveis. Essa, desde cedo, foi uma visão de grande parte dos atores envolvidos. Só uma abordagem ampla do problema, de forma a contemplar distintas competências técnicas, legais e políticas, poderia ter consistência suficiente para produzir efeitos transformadores da realidade observada. Intersetorialidade e interinstitucionalidade foram palavras de ordem a impregnar o debate.

As universidades e centros de pesquisa passaram a engajar-se como agentes quase "naturais" nessa caminhada, convocados a colocar sua experiência investigativa em favor da produção de conhecimento sobre o tema.

Um marco importante para que isso ocorresse foi a realização, pelo Governo Federal, de uma grande oficina sobre o trabalho infantil em Brasília, no ano de 1996, que incluiu alguns dos mais importantes centros brasileiros de pes- 
quisa em ciências sociais e saúde, ocasião em que algumas experiências de serviço e pesquisa foram debatidas ${ }^{6}$.

A integração dos pesquisadores e seus centros orientou-se sob uma referência na qual se combinaram indignação e solidariedade, sem falar de uma certa dose de surpresa e perplexidade a respeito. Pode-se dizer que uma questão fazia-se presente em grande parcela dos estudiosos: "como não percebemos isso antes?" O envoltório institucional que marcava o evento era demasiado denso ${ }^{7}$ para que se duvidasse da importância atribuída à temática e de tudo que se esperava dos novos parceiros.

Se o trabalho infantil/precoce não era coisa nova enquanto prática social - havia se tornado "paisagem natural" na vida do país -, na verdade, a temática, centrada na infância e adolescência, escancarava os numerosos aspectos destrutivos que não recebiam a devida atenção da pesquisa, numa ordem sócio-econômica já prenhe de iniqüidades. Um artigo na Internet chama a atenção para essa lacuna de sensibilidade e conhecimento:

Até meados dos anos 80, o trabalho infantil não chegava a se constituir num tema que despertasse interesse da sociedade. Pensavam muitos, até então, que o trabalho de crianças era uma alternativa positiva, disciplinadora e de ajuda à família. Em todo mundo o tema despertava mais apatia, indiferença ou cinismo do que preocupação. Até então a única instituição internacional preocupada e empenhada em erradicar o trabalho precoce era a Organização Internacional do Trabalho (OIT). (Maes, s.d.)

Apenas alguns poucos cientistas sociais brasileiros como José de Souza Martins e Cheiwa Spindel - ao menos entre os nomes mais conhecidos na academia - já haviam se debruçado sobre a centralidade da violência que atingia crianças e adolescentes através da exploração pelo trabalho. Tal conteúdo era tratado lateralmente em quase todas as ciências sociais e negligenciado pela maioria da sociedade. Quer dizer, o reconhecimento de um dos tantos reveses de nossa economia e vida social, foi alçado à condição de tema de pesquisa, colocando no centro do foco as vidas e horizontes de crianças e adolescentes, configurando-se, dessa forma, como novidade. Em consequiência, determinou desafios metodológicos e conceituais em cada um dos recortes sobre os quais as diversas áreas de estudo passaram a debruçar-se.

A reunião entre pesquisadores e instituições funcionou como uma grande catarse. A troca de experiências no combate ao trabalho infantil e os projetos de investigação que já se achavam em andamento ou concluídos, assentaram as bases da nova linha de investigação. Reconhecida a existência do problema em suas dimensões mais gerais, e mesmo, as particularidades de algumas experiências pontuais, esperava-se da academia uma contribuição decisiva para a compreensão do fenômeno em extensão e profundidade. Um aspecto chamava a atenção: a convocatória do evento acenava com suporte financeiro para empreendimentos de pesquisa contando principalmente com resultados práticos, delineando o caráter instrumental da agenda de investigação. A qualidade técnica das propostas dos diversos centros brasileiros de pesquisa passou também pelo crivo do acento pragmático que definiu os critérios de seleção dos projetos concorrentes.

\section{Consensos e controvérsias}

Centrando o olhar sobre o trabalho precoce como um objeto especial, algumas questões passam a defini-lo como um recorte legítimo e desvelador de nacos importantes da realidade sócio-econômica: uma delas diz respeito à impressionante abrangência e multiplicidade de tipos de inserção de crianças e adolescentes no trabalho e, em conseqüência, faz com que uma parte significativa da economia brasileira seja "tocada" por eles.

A produção acadêmica e das agências de governo ou internacionais têm tratado do tema muito mais do ponto de vista dos aspectos fenomênicos produzidos em cada contexto onde o trabalho infantil está presente, do que produzido análises onde se articulem esses componentes das diversas dinâmicas a quadros teóricos. Se o objeto, em sua configuração de prática social há pouco reconhecida, ainda não foi suficientemente analisado para produzir uma "teoria" ou teorias que expliquem especificamente a gênese do trabalho precoce nos termos de sua ocorrência atual, por outro lado, a teoria marxiana de exploração e alienação do trabalho, como componente central da dinâmica capitalista, tem surgido como um suporte teórico potente em alguns trabalhos a sustentar que a exploração infantil pelo trabalho tem lugar no conjunto do processo de exploração capitalista, da produção da mais-valia e da acumulação crescente ${ }^{8}$. Nesse sentido, as condições de pobreza e exclusão social, consideradas como fontes geradoras ou facilitadoras da inserção precoce no trabalho, seriam apenas contingentes ao curso do desenvolvimento capitalista em que, contraditoriamente, se misturam robótica, mundialização dos mercados, alta competividade empresarial e miséria social crescente. A ocorrência dessa combinação pode ser detectada em várias cadeias produtivas que, em algum de seus pontos, usufruem a superexploração do trabalho informal, terceirizado ou quarteirizado, incluindo a mão-de-obra infantil e/ou infanto-juvenil. Se essa linha de raciocínio faz sentido como processo explicativo de tantas formas de trabalho infantil, ela conta com limites quando se trata de indagar sobre as estratégias a serem desencadeadas para a prevenção e eliminação do trabalho precoce. Se o capitalismo é a matriz de todos os males, qualquer medida que se tome para reduzir a pobreza, aumentar os recursos educacionais, vigiar os abusos e burlas, garantir mínimos sociais, aumentar oportunidades econômicas e cul- 
turais de várias ordens para famílias, crianças e adolescentes, não passariam de um verniz efêmero a ser destruído pela lógica dominante. A literatura sobre trabalho infantil tem tornado evidente as estratégias do capital em garantir força de trabalho servil, desorganizada e abundante, que garanta custos baixíssimos em algum ponto das cadeias produtivas. Pesquisa da Fundação Abrinq

apontou que gigantes nacionais e multinacionais se beneficiavam do trabalho infantil. O carvão vegetal produzido ilegalmente ... na região de Bocaiúva era comprado pelas siderúrgicas Lucape, Gerdau, Barra Mansa e Açominas, todas produtoras de matérias-primas para a White Martins, a Sisco e a Belgo-Mineira. ... A Belgo-Mineira vendia chapas para a fabricação de automóveis à Volkswagen do Brasil e à Mercedez-Benz, além de fornecer a base dos produtos da Bombril. O carvão da fazenda Italmagnésio, também produzido com a utilização do trabalho infantil mineiro, era adquirido pela siderúrgica do mesmo nome, que vendia ferro-gusa à Cosipa, à Acesita e à Belgo-Mineira, uma fornecedora da General Motors e da Fiat, entre outras megaindústrias. (Cipola, 2001, p. 36)

A lista é grande e inclui uma série de ramos produtivos que possuem peso econômico muito grande na balança comercial brasileira, como os ramos calçadista, fumageiro, de suco de laranja, canavieiro, todos fortemente orientados para a exportação. Visto dessa forma, o tema do trabalho infantil insere-se, sem dúvida, num cenário muito amplo, definidor de alguns aspectos que caracterizam a estrutura do modelo de desenvolvimento capitalista brasileiro, estando colado a ele e não externo, como algumas considerações possam sugerir. Tratar-se-ia, portanto, de uma determinação estrutural em que as medidas voltadas para os contingentes submetidos a ela na forma de programas ou ações pontuais teriam efeito passageiro, com todas as possibilidades de retorno à situação anterior, na medida que não transformariam aspectos fundamentais das relações econômicas.

Ora, tal entendimento define como horizonte a transformação do modelo de desenvolvimento e, no limite, a erradicação do capitalismo como modelo de sociedade. A baixa probabilidade de que tais fatos ocorram pode produzir um quadro de desânimo e cinismo nos agentes sociais sensibilizados com a causa de crianças e adolescentes explorados. Se o capitalismo é onipresente, transnacional, com todos os recursos tecnológicos à sua disposição para tomadas rápidas e profundas de decisão sobre seus rumos, os estados nacionais democráticos, ainda podem e devem exercer papel modulador no processo de desenvolvimento, freando alguns pontos críticos onde sobressai a voracidade por práticas de superexploração. Se o processo de exploração do trabalho é inerente ao capitalismo, a história moderna das sociedades burguesas atesta pontos importantes de inflexão na selvageria através da dimensão política, em que as políti- cas públicas firmaram patamares crescentes de regulamentação do contrato.

A cena atual é amplamente desfavorável ao investimento político das sociedades que padecem de altas taxas de desemprego, reestruturação produtiva galopante, dívida externa, constrangimentos comerciais, submissão às fórmulas do Fundo Monetário Internacional, como é o caso brasileiro. No entanto, a sociedade organizada constituiu, nas últimas décadas, espaços para debater aspectos fundamentais como o da fúria discursiva desregulamentadora - discursiva, porque se deseja tornar oficial e justificada consensualmente, $o$ que já existe na prática - colocando em risco direitos trabalhistas assentados há meio século. Se a sociedade organizada puder intervir nesse campo, estará dando um salto de qualidade em termos de ação efetiva para coibir alguns dos aspectos mais destrutivos da economia capitalista. Nesse caso, todas as políticas dirigidas às várias dimensões que dizem respeito à constituição da infância e adolescência e de redução da pobreza podem ser potencializadas em seus efeitos.

O debate sobre a gênese do trabalho infantil vem sendo trabalhado com dificuldades no cruzamento entre a reflexão acadêmica e o ímpeto interventor de organizações não-governamentais, setores de governo e outros setores envolvidos. O pragmatismo intervencionista e a tradicional elaboração acadêmica dos fatos, demorada, não têm, com algumas exceções, proporcionado oportunidades mais freqüentes de fertilizarem-se mutuamente; há uma defasagem temporal e obstáculos político-institucionais que dificultam esse processo. Isso significa que o alcance das ações para prevenção e combate ao trabalho infantil podem ser potencializados à medida que os diagnósticos estejam mais sintonizados com a realidade, definindo quais os componentes principais definidores da realidade de meninos e meninas.

A seguir são apresentados resultados de alguns estudos que revelam a amplitude e complexidade de realidades diferenciadas onde o trabalho infantil é uma realidade expressiva.

Em relatório de pesquisa realizada entre 1993 e 1996 em Porto Alegre, já chamava a atenção deste autor o número significativo de acidentes com jovens até 17 anos em empregos do mercado formal. O estudo de cerca de 2800 acidentes do trabalho de trabalhadores urbanos segurados do INSS evidenciava dois aspectos muito importantes a despertar para o tema do trabalho precoce: a enorme variedade de inserções de adolescentes no mercado formal de trabalho e a fantástica multiplicidade de tarefas a seu encargo, lidando com todo o tipo de tecnologia, tornando-os um grupo relevante de risco (Ferreira \& Valenzuela, 1998). Atuam como fatores desfavoráveis o baixo nível de escolaridade, a ausência de políticas de capacitação para o trabalho e uma 
fluidez completa que lhes imprime a condição de trabalhador generalista, pronto para qualquer tarefa. Esta característica justifica sua utilização como "pau para toda obra", condição em que o desvio de função é uma constante, levandose em conta as razões alegadas para sua contratação em contraposição com as funções que exerce.

Essa era uma pequena amostra do significado real do trabalho precoce, na medida que apenas parte do mercado de trabalho estava representado: uma amostra dos trabalhadores do mercado formal, acidentados em Porto Alegre durante um ano. Um dado importante que se destaca naquele estudo é a presença significativa de adolescentes (havia um caso com 13 anos de idade) em atividades formais. Ela era decorrente de uma legislação que estimulava esse procedimento: a legislação por cotas imposta às empresas, segundo a qual

Os estabelecimentos industriais de qualquer natureza, inclusive de transportes, comunicações e pesca, são obrigados a empregar, e matricular nos cursos mantidos pelo Serviço Nacional de Aprendizagem Industrial (SENAI):

a) um número de aprendizes equivalentes a $5 \%$ no mínimo e $15 \%$ no máximo dos operários existentes em cada estabelecimento, e cujos ofícios demandem formação profissional (Art. 429 da CLT)

O contrato de aprendizagem é o contrato de trabalho especial, em que o empregador se compromete a assegurar ao maior de quatorze anos e menor de dezoito anos, inscrito em programa de aprendizagem, formação técnica-profissional metódica, compatível com o seu desenvolvimento físico, moral e psicológico, e o aprendiz, a executar, com zelo e diligência, as tarefas necessárias a essa formação. A formação técnico-profissional mencionada caracteriza-se por atividades teóricas e práticas, organizadas em tarefas de complexidade progressiva desenvolvidas no ambiente de trabalho.

Ora, essa definição raramente foi cumprida à risca, tornando-se uma brecha na legislação para a contratação de força de trabalho adolescente sem as obrigações celetistas relativas à mão de obra adulta. Assim, se o espírito da lei era o de criar espaços de aprendizado profissional para jovens carentes, a prática revelava uma negligência completa desse aspecto, pois as empresas utilizavam as facilidades da lei para contratação de mão-de-obra juvenil na forma de um mecanismo de substituição de mão-de-obra adulta e redução de custos operacionais.

Nem os princípios da Convenção das Nações Unidas sobre os Direitos das Crianças e da Convenção 138 da OIT, com desdobramentos na elaboração do Estatuto da Criança e do Adolescente, chegaram a promover impactos nesse âmbito, levando algum tempo para revelar o significado do trabalho precoce e suas consequiências. A própria legislação, um produto histórico da combinação de interesses em- presariais, concepções autoritárias e tutelares em relação às classes populares, eugenia e higienismo, funcionou como facilitadora do processo de exploração (Ferreira, 1999).

Como todo fenômeno social recém-descoberto também o trabalho precoce padeceu - e ainda padece - de imprecisões nos números, para mais ou para menos, exageros, distorções, ênfases na publicização de situações extremas a ressaltar seus aspectos de tragédia social. A tragédia existe e está muito distante de um horizonte que favoreça sua redução drástica como chaga social, mas, ao mesmo tempo, ela compreende um mosaico muito variado de situações que precisa ser melhor conhecido. O papel dos meios de comunicação foi decisivo para fomentar o debate público e explicitar o conflito de posições sobre o tema. Seu efeito dramatúrgico teve o poder de expandir, dar eco às dificuldades de crianças com sua infância desmantelada pela pobreza e o trabalho, revelando as mutilações, as imagens sombrias das carvoarias, os riscos abusivos, a desnutrição em meio a estatísticas com um grau importante, mas não negligenciável, de variabilidade.

Ensaio de Schwartzman (1996), analisando dados do PNAD de 1995, refuta algumas afirmações e cálculos de aproximadamente "500.000 crianças exploradas" no país entre 5 e 9 anos de idade, o que, segundo o autor não corresponderia à realidade dos fatos. Das 580 mil trabalhadoras existentes - dado que considera dramático - o contingente maior estaria no campo (420 mil), contra 27 mil das áreas metropolitanas. No entanto, assinala que as denúncias de exploração feroz em canaviais e carvoarias, entre outras atividades penosas, que passaram a povoar o noticiário de televisão, seriam expressão de situações especiais que corresponderia apenas à pequena parte do grande volume de mão de obra infantil detectado nos dados. Em decorrência, aponta que a pobreza no campo, a questão fundiária, o baixo nível de instrução das famílias e a grande precariedade dos serviços públicos seriam os determinantes mais potentes desta realidade do trabalho infantil. Não se trataria, portanto, de um quadro de exploração direta em toda sua extensão, como a propaganda e os debates deixavam transparecer. Detecta, ainda, que cerca de 5\% dessas crianças têm sua escolaridade prejudicada pelo trabalho.

O objetivo do ensaio é o de chamar a atenção para os vários agentes envolvidos com o combate ao trabalho infantil, de que essa é uma realidade estrutural cujas soluções passam pelo ataque à pobreza, onde as políticas de governo ganham destaque: reativação e estabilização da economia, políticas de desenvolvimento, melhoria do sistema educacional, reordenamento do sistema fundiário, são as linhas mestras desse grande empreendimento.

Transparece um receio de que se lance mão de medidas como boicote a produtos brasileiros, ou seja, "barreiras mo- 
rais" que poderiam trazer resultados nefastos para o país com impactos negativos profundos sobre o conjunto da economia.

O argumento baseado em evidências empíricas é de grande respeitabilidade, mas não é suficiente para captar a extensão de causas e danos dessa realidade, nem de entendêla em alguns de seus fios mais finos dos nexos entre estruturas e processos sociais, antecedentes e resultados. Se a pobreza das regiões e famílias aparece como dado muito persistente, por outro lado ela não é o elo explicativo de um grande número de inserções precoces e todas suas conseqüências ${ }^{9}$.

Estudo promovido pelo Ministério do Trabalho e OIT entre 1998 e 1999 em 3 estados nordestinos, compreendendo 5 municípios e 4 áreas produtivas, revelou alguns aspectos importantes de cenários muito particulares, mas que podem servir de referência para armar as lentes no exame de outras realidades particulares ${ }^{10}$.

O recrutamento da força de trabalho infantil dá-se, no conjunto das áreas, a partir dos cinco anos ${ }^{11}$, que já compreende, nesta faixa, $1 \%$ de toda a força de trabalho até 17 anos. $15 \%$ dos trabalhadores estão entre 5 e 9 anos, $45 \%$ entre 10 e 13 anos e, $38 \%$ entre 14 e 17 anos. Na amplitude de faixa etária estudada (até 17 anos) encontramos a frequiência acumulada de $60,1 \%$ até 13 anos completos.

A desagregação dos dados por áreas produtivas ou municípios revela algumas diferenças importantes, mas o conjunto é muito rico na revelação de algumas marcas que são comuns e que podem repetir-se em outros estudos da mesma natureza em outros espaços e atividades. As áreas estudadas apresentam taxas de pobreza com valores muito acima da média brasileira, famílias numerosas - com média de 6,2 pessoas por domicílio - e uma renda per capita média de 32,37 reais. A renda média dos domicílios é de 250,30 reais. $62,8 \%$ dos chefes de domicílio não possuem escolaridade ou freqüentaram no máximo, um ano de escola. Cerca de $71 \%$ das mães das crianças e adolescentes trabalhadores apresentam entre 4 e 12 gestações e $7,5 \%$, entre 13 e 15 gestações, completando quase $80 \%$ da amostra. $38,4 \%$ dessas mulheres tiveram espaços intergestacionais até um ano, enquanto $39,7 \%$, entre 1 e 2 anos, justificando a extensão das proles. Por sua vez, apenas 53,6\% delas freqüentaram um programa mínimo de pré-natal, condição que se mostrou muito grave em Arapiraca (AL), onde apenas 37,2\% das gestantes tiveram acesso a este recurso de saúde.

O conjunto dos dados revela uma situação de completo abandono dessas famílias em realidades onde pouco podem fazer para superar sua condição de excluído. Seu nível de autonomia é tendente a zero, na medida que se encontram totalmente desprotegidas de políticas que confiram algum suporte social. A condição de vulnerabilidade trespassa a condição sócio-econômica e a absoluta falta de oportunidades e combina-se aos riscos inerentes a atividades laborais como a exposição a pesticidas (fumo), produtos químicos (tecelagens), fibras (tecelagens), cortes e queimaduras (casas de farinha), acidentes no transporte (citricultura), quedas de nível (citricultura), transporte de sobrepeso (citricultura), posições antiergonômicas (tecelagens), jornadas extensas com fadiga excessiva (citricultura, casas de farinha e tecelagens), ganhos de produtividade (citricultura), superexposição às adversidades climáticas (sol, calor, frio, umidade, chuva) entre outros. O quadro clínico de crianças e adolescentes deste estudo revela que:

as alterações ósteo-musculares compõem mais de 16,4\% dos achados, e evidenciaram a gravidade do surgimento precoce de deformações, assimetrias, contraturas musculares, saliências de ombros e escápulas, que desenham um quadro grave de alterações importantes do eixo da coluna vertebral de crianças e adolescentes, como escolioses, cifoescolioses e lordoses, muitas delas em estado avançado. ... a prevalência mais importante foi detectada naqueles setores de atividade em que crianças e adolescentes são mais exigidos quanto a posturas antiergonômicas e o transporte de pesos excessivos, como nas tecelagens e casas de farinha no Rio Grande do Norte e citricultura de Sergipe (Ferreira, 1999).

Com muita freqüência, as jornadas extensas e de alto risco têm seus efeitos adversos potencializadas pelas condições de baixa ingesta e conseqüente mau estado nutricional. Os dados antropométricos revelaram, neste estudo, um quadro grave de $90,8 \%$ de desnutrição moderada e 9,2\% de desnutrição severa com relação ao índice idade-altura, que significa comprometimento irreversível do crescimento em função da agressão crônica e prolongada ao organismo.

Quer dizer, esses são resultados que marcam experiências coletivas de trabalho cujos efeitos adversos só vão repercutir sua magnitude de forma indireta, ou seja, nas estatísticas de novas gerações de trabalhadores muito jovens, sem instrução, com proles numerosas, desnutridos e abandonados. Os dramas pessoais e familiares permanecem nas sombras, iluminados apenas em reportagens esparsas, para mergulhar depois no esquecimento quase completo.

Outro estudo (Silva, 2000) realizado no meio rural de Santa Cruz do Sul, trabalhou com o processo de construção da identidade feminina em meninas até 14 anos, que ingressaram precocemente no trabalho, seja na lida da lavoura do fumo, seja no apoio logístico que dão à família, realizando a maioria dos trabalhos domésticos, que inclui cuidar dos animais, arrumar a casa, cuidar de irmãos, fazer as refeições, entre outros. Os achados da autora revelam com nitidez que as referências afetivas, principalmente em sua identificação com a figura materna, sofrem interferências severas de sua condição de menina trabalhadora. Raros são os sinais de 
acolhimento e proteção, com exacerbação do senso de responsabilidade e dever, anulando todo o espaço para desenvolvimento do lúdico. A relação com as figuras paternas se faz exclusivamente por intermédio das expectativas e desempenhos que filhas e pais colocam no trabalho. Os testes de Apercepção Temática com figuras de animais mostraram relações calcadas no medo da punição e desejos muito fortes de fuga de casa e, mesmo, de morte dos pais. As expectativas de realização pessoal são reduzidas ao gerenciamento do espaço da casa e ao matrimônio, com manifestações freqüentes de reconhecimento de uma incapacidade pessoalprincipalmente no plano intelectual - que as impedem de desejar algo mais como estudar, chegar à universidade ou exercer ofícios que exijam algum aprimoramento intelectual.

Flávia Hoelzel, em estudo realizado no mesmo município, mas em regiões diferentes, trabalhando com a noção de ideologia englobante de Louis Dumont, recupera os caminhos percorridos por meninos e meninas entre 9 e 14 anos, na sua trajetória rumo ao abandono da carreira escolar. Segundo a autora, são visíveis os marcos da quarta série do curso básico e a oitava série como momentos críticos para o abandono do estudo. A abordagem etnográfica articulada ao referencial dumontiano permite desenhar um tecido de influências sobre crianças e adolescentes operado pela família, escola, comunidade em geral, todos subsumidos ao discurso ideológico de indispensabilidade da indústria fumageira. Esta, ao estabelecer os vínculos econômicos com os pequenos produtores, exige deles uma lealdade que se consubstancia em metas de produtividade, adoção de modelos tecnológicos, supervisão permanente do plantio, além da submissão ao preço final do produto, quase sempre abaixo do esperado. O quadro de domínio - econômico e ideológico - se completa através da construção de imagens institucionais pela indústria que se impõe à opinião pública através da propaganda, pela concessão de benefícios secundários como apoio a atividades esportivas e culturais, manutenção de logradouros públicos etc., legitimando sua fixação como personagem de inquestionável valor no imaginário popular. Os depoimentos de diferentes atores sociais podem até conter críticas ao sistema implantado, mas não conseguem estabelecer rupturas discursivas, não ousam ou conseguem atravessar alguns limites claros impostos pela ideologia que os massacra.

Para as famílias do meio rural essa configuração tem seu valor potencializado pelo vínculo econômico. Além disso, a herança germânica do valor do trabalho responde aos desejos dos dominadores com uma lealdade incondicional, mesmo que essa atitude produza impactos destrutivos em várias dimensões da vida pessoal e familiar. A fala de um agricultor que justificava seu desejo de resgatar seu filho estudante para o trabalho, já que havia ultrapassado a quarta série é ilustrativa demais para não ser citada:

Se já passou da quarta série já sabe o suficiente pra por comida na mesa; além disso, aqui não é lugar de vagabundo!

Essa subvalorização do conhecimento escolar como recurso importante, inclusive para repensar as estratégias de mudança e o desvencilhamento do domínio, tem seu complemento nas dificuldades objetivas de acesso à escola, principalmente após a quarta série, pois existem em toda a área rural de Santa Cruz do Sul, apenas duas escolas com o primeiro grau completo. O trabalho na lavoura exige a permanência de meninos e meninas fora da escola, além da qualidade discutível dessa escola que insiste em permanecer alheia aos sonhos e desejos de sua clientela. Na passagem da infância para adolescência os jovens vão trabalhando e sendo submetidos a todo tipo de sedução para que não abandonem a terra e o trabalho. Interessante observar que no jogo de sedução a palavra trabalho pode ser deslocada-já que seu significado tem sofrido críticas em se tratando de infânciapara a palavra "ajuda". Ela ainda é infensa a ataques mais sérios e definitivos, carregando nessa pretensa inocência retórica o aprofundamento progressivo das responsabilidades e envolvimento com o trabalho e suas conseqüências.

Essas considerações vão ao encontro do afirmado anteriormente: se os estudos de dimensão macro apontam grandes linhas de comportamento social, político e econômico, servem, por isso mesmo, para servir de guia para novas explorações e aprofundamentos em planos que permanecem desconhecidos.

De agora em diante, passado o período de grandes balanços, a experiência mostra que a necessidade é de redesenhar os processos de investigação dotando-os de olhares mais finos, buscando apreender aspectos mais sutis em cada uma das numerosas realidades locais/regionais, com o propósito de absorver e compreender aspectos específicos, muitas vezes exclusivo, com determinantes pouco visíveis, mas necessários de serem apreendidos, sob pena de, uma vez deixados de fora ou não compreendidos, tornarem-se obstáculos importantes nas ações de combate ao trabalho precoce.

A proposta é de incorporação crescente de áreas de conhecimento ainda não envolvidas ou, envolvidas de forma incipiente na pesquisa sobre trabalho precoce, com intervenção de especialistas em cada um dos campos, abrindo frentes de investigação inovadoras para compreensão não apenas dos determinantes, mas também dos desfechos produzidos pela inserção precoce no trabalho.

Cito como exemplo uma série de estudos ainda não realizados no campo das ciências biomédicas voltados para a infância e adolescência, para desmistificar concepções que 
teimam em afirmar sobre a inocuidade do trabalho precoce: repercussões neurológicas, dermatológicas, sobre o sistema neuroendócrino, o sofrimento/impacto provocado pelo trabalho precoce no sistema miotendinoso, as deformações ósseas, estudos epidemiológicos sobre desfechos como intoxicação crônicas e acidentes, estudos sobre o desenvolvimento físico-mental e emocional das crianças - esses, em estreito contato com profissionais da área psi e educação, com foco sobre aspectos do desenvolvimento cognitivo, desenvolvimento da linguagem, aprendizado escolar, entre outros recortes. A área de educação precisa conhecer melhor o sentido atribuído à escola e ao trabalho por crianças e adolescentes expostos à exploração em busca de práticas pedagógicas que a tornem um espaço estimulante e referência importante nas vidas de sua clientela. A área da saúde, por sua vez, tem negligenciado as relações entre saúde e trabalho, resultando num desconhecimento quase completo sobre os impactos dos diversos tipos de trabalho sobre a saúde e desenvolvimento físico. Todos os esforços por construir modelos de atenção à saúde do trabalhador no país inteiro esbarram em dificuldades estruturais, entre elas, a da formação insuficiente dos técnicos saídos dos cursos da área de saúde.

No caso da criança trabalhadora, então, existe um vazio imenso que, a par da contradição que possa expressar, precisa ser, de alguma forma, preenchido como espaço de atenção e pesquisa ${ }^{12}$.

Estudos sócio-antropológicos ou psicossociais com o objetivo de captar/apreender aspectos referentes à esfera dos diversos níveis de interação - familiar, grupal e societária mais ampla - e sociabilidade, revelando características de suas vivências, desejos, interesses, sonhos e expectativas são também desejáveis. As subjetividades apreendidas como representações sociais de grupos e comunidades podem também ser articuladas às formas de ocupação do espaço trabalhadas pelos geógrafos, aos estudos de movimentos de população, sinalizando para os modelos de ocupação da terra, e os conflitos entre forças locais e regionais, de modo a evidenciar as linhas de força que configuraram os desenhos societários atuais e os principais fatores de subjugação em jogo.

Além disso, estudos dos grupos familiares e comunitários com laços mediados pela prática do trabalho infantil merecem estudos qualitativos que apreendam o conjunto de razões de natureza local que chancelam a tomada de decisão de responsáveis pela entrada de crianças no trabalho.

Isso não significa, contudo, cair na cilada de definir os microespaços sociais como responsáveis exclusivos ou maiores na decisão de colocar crianças a trabalhar, mas sim, apreender como se articulam os vários pontos de um cenário mais amplo que implica estratégias de várias naturezas, onde a economia regional - com um certo limiar de "solida- riedade econômica" que atravessa aspectos mais sutis de dominação social - permite acordos silenciosos para "tocar" a economia, significando as bases de organização dos interesses empreendedores, constituição das potencialidades e disponibilidades do lugar, ou seja, o que os economistas definem como vantagens comparativas.

Entre essas, a disponibilidade de mão de obra infantojuvenil é um dos componentes mais visíveis desta potencialidade. Se o aparelho escolar é precário, distante e nada estimulante na sua oferta pedagógica, essa potencialidade se desloca facilmente para o lado do trabalho, aliando necessidades e carências com um, a princípio, vago e indefinido "interesse" em trabalhar, que se amplia na medida da vivência da própria inserção e a emergência de desejos de consumo com o passar do tempo.

\section{Considerações finais}

As variáveis são muitas, masé profundamente necessário debater e interferir decisivamente - e com conhecimento de causa - no perfil das políticas públicas nos vários níveis de sua formulação e execução. Os esforços que muitos municípios têm realizado na tentativa de compor um painel de políticas cujo alvo é a infância e a adolescência têm gerado mares de equívocos - em boa parte dos casos - de boa vontade. Em primeiro lugar a ocorrência de trabalho infantil tem sido compreendida como um problema social a mais, desarticulado dos componentes macroeconômicos que o produzem. Pobreza e estagnação econômica têm sido culpadas pela produção do fenômeno, embora as estatísticas revelem que mercados de trabalho que "absorvam as pessoas interessadas em trabalhar", como no Sudeste mais rico, determinam taxas de atividade semelhantes às do Nordeste mais pobre.

Além de uma visão localista do fenômeno, as iniciativas ainda padecem de referências mais atualizadas sobre o significado da infância e da adolescência, produzindo ações ainda impregnadas ou orientadas, antes de tudo, de um sentido disciplinador, com forte acento autoritário e moralizante. As preocupações de gestores públicos e técnicos de programas e políticas carregam muitos preconceitos e com eles atuam em sua prática pedagógica. Quer dizer, muito pouco que possa merecer a definição de alguns dos preceitos já tão discutidos em fóruns internacionais sobre direitos da infância e adolescência que, de algum modo, estão assentados na estruturação do ECA.

Os exemplos são muitos, e os conselhos tutelares ilustram as afirmações acima pautando sua atividade de forma corretiva, com uma ênfase policialesca em lugar de instituirse como uma instância mediadora dos conflitos com crianças e adolescentes. Por sua vez, as instituições com o poder delegado de organizar ou vigiar os termos de convivência dos envolvidos em outras bases, o poder judiciário, por exem- 
plo, ainda vivem no tempo do "menor", com todo o resquício excludente que o termo carrega desde o Estado Novo.

Acolhimento, proteção e compreensão seriam os marcos desejáveis da ação institucional nas áreas de educação, assistência social e justiça. No entanto, há muito conhecimento a produzir para adequar medidas que sejam libertadoras, promotoras da condição de cidadania, propulsoras da autonomia social aos milhares de micro-espaços do país.

Relatório recente do IBGE revela que a par do avanço que o país experimentou na década passada em relação a alguns indicadores, fato amplamente divulgado na imprensa, lamentavelmente dois deles persistem como mácula de uma sociedade que não consegue resolver um problema básico: a desigualdade social está maior. O outro, diz respeito ao recrudescimento da mortalidade de jovens por causas externas.

Se o primeiro - a desigualdade - desdobra-se em inúmeros outros processos que são contra a saúde, a educação, o trabalho, a cultura, a autonomia, a justiça, a solidez dos laços afetivos, contra a vida, enfim, o segundo - o aumento da mortalidade de jovens - é manifestação extrema desses tantos resultados indesejáveis. No caso específico, o quadro de desigualdades de renda e de oportunidades conta com uma mediação importante a exacerbar a exclusão: trata-se do sistema escolar, levando-se em conta seu papel fundamental de espaço de socialização.

Há mais de uma década que a fragilidade da escola impede que seja reconhecida como referência fundamental para sedimentar valores junto aos alunos. O esvaziamento de seu papel formador transforma a relação alunos-escola em laços frouxos, sem maiores conseqüências para estimular consideração pelo outro, solidariedade e respeito à vida. A conseqüência mais funesta tem sido a de tornar qualquer experiência social um palco para alimentar o narcisismo e praticar o individualismo desmedido, onde tudo aquilo que não reverta em ganhos pessoais, perca seu significado. É um passo decisivo para banalização da vida. Rizzini (1997), ao analisar o espírito que sempre governou as políticas brasileiras para infância nos séculos dezenove e vinte, refere-se à combinação entre paternalismo e repressão e arbítrio que manteve os excluídos em seu lugar. Em primeiro lugar, as estratégias selecionadas para a intervenção estatal não visavam outra coisa senão promover uma reordenação do poder vigente.

Substituir as estratégias aniquiladoras da cidadania por instrumentos de construção de autonomia social significa politizar o tema do trabalho infantil, impregnando a reflexão e as ações para seu combate, do sentido conflituoso que ele possui na raiz: evitá-lo e combater as formas existentes exige mobilização social intensa em que os atingidos necessitam compreender os motivos das mudanças necessárias, evitando novas formas de manipulação e construção de novas subalternidades.

\section{Referências}

Bequelle, A., \& Myers, W. E. (1995). First things first in Child Labour: Eliminating work detrimental to children. Geneva: International Labour Organization.

Brasil. (1998). Constituição: República Federativa do Brasil. Brasília: Senado Federal, Centro Gráfico.

Campos, H. R. (2001). Pobreza e trabalho infantil sob o capitalismo. Tese de Doutorado não-publicada, Universidade Federal do Rio Grande do Norte, Natal.

Cipola, A. (2001). O trabalho infantil. São Paulo: Publifolha.

Ferreira, M. (1999). Investigação dos comprometimentos do trabalho precoce na saúde de crianças e adolescentes (Relatório de Pesquisa). Brasília: MTb/OIT.

Ferreira, M. A. F., \& Valenzuela, M.C. (1998). Estudo epidemiológico dos acidentes do trabalho em Porto Alegre (Relatório Final de Pesquisa, Financiamento: FAPERGS). Porto Alegre: Escola de Saúde Pública.

Hoelzel, F. (2000). O trabalho precoce e projetos de vida: um estudo em crianças e adolescentes do meio rural de Santa Cruz do Sul. Dissertação de Mestrado não-publicada. Universidade de Santa Cruz do Sul, Santa Cruz do Sul.

Human Rights Watch [HRW] (2001). Children's rights. Disponível em http://www.hrw.org/children.

International Labour Organization [ILO] (1997). Child labour: What is to be done. Disponível em http://www.ilo.org/public/english/bureau/inf/ speeches/ab.htm.

Maes, P. R. (s. d.). O trabalho infantil. Disponível em http://www.melim.com/ abrhitj/ab_infantil.htm.

Organización Internacional del Trabajo [OIT]. (1993). Trabajo. Revista de la OIT, 4, 4.

Rizzini, I. (1997). O século perdido. Rio de Janeiro: USU.

Schwartzman, S. (1996, 27 de dezembro). O trabalho infantil. Jornal do Brasil, p. 9.

Silva, R. B. F. (2000). Trabalho infantil e construção da identidade de gênero. Dissertação de Mestrado não-publicada, Universidade de Santa Cruz do Sul, Santa Cruz do Sul.

United Nations [UN] (1989). Convention on the Rights of the Child. (U.N. General Assembly. Document A/RES/44/25-12 December 1989). Disponível em http://www.hrweb.org/legal/child.html.

United Nations [UN] (2000). Declaration of the Rights of the Child (Proclaimed by General Assembly resolution 1386-XIV of 20 November 1959). Disponível em http://www.unhchr.ch/html/menu3/b/25.htm.

\section{Notas}

1 Os termos trabalho precoce e trabalho infantil serão utilizados de forma intercambiável neste artigo, mesmo que o autor prefira o primeiro, por qualificar a entrada no mundo do trabalho como um evento antecipado, 
aquém do regularmente esperado, seja para crianças como para púberes e adolescentes jovens. O segundo termo está consagrado como entrada para a pesquisa bibliográfica nas diversas bases de dados, mesmo quando a referência não trate exatamente de trabalho infantil stricto sensu, ou não seja seu tema central. A diferença entre os termos pode tornar-se significativa com o passar do tempo, na medida que o desenvolvimento teórico-conceitual exija maior precisão em seu uso.

2 A notícia mais recente divulgada pela Agência Brasil, durante a abertura do Fórum Nacional de Erradicação do Trabalho Infantil é de que o país já conseguiu alcançar a meta de retirar 392 mil crianças do trabalho. A informaçãoé de autoria da Secretária Wanda Engel e pode ser encontrada em http://www.igi.com.br/ nome/editorial.

3 "Os conselhos são órgãos paritários, compostos por representantes do poder público e entidades da sociedade civil, cuja função é deliberar, formular e controlar as políticas de atendimento a crianças e adolescentes em âmbito municipal, estadual e nacional". (In: http://tributoacidadania.unafisco.org.br/textos/conselhos.htm)

4 A Lei Orgânica de Assistência Social-LOAS, seus princípios, propósitos e desdobramentos na prática não se encontram desenvolvidos neste artigo.

$5 \quad$ Uma das pontas dessa grande colcha de retalhos que agride persistentemente a sociedade, tornando-a um espectador envergonhado e impotente diante dos fatos, é a sucessão de episódios das FEBEMs, uma espécie de antesala do sistema prisional brasileiro. São incontáveis os equívocos praticados desde as primeiras decisões tomadas em relação a meninos e meninas que os agentes sociais rotulam como "infratores", até essa ponta explosiva e mais visível (e temida) do problema pelo grande público. A consequiência mais imediata no imaginário popular é de enxergar a ampliação das medidas repressivas como a única solução cabível. Neste sentido, o ECA seria um instrumento suavizador das penas e estimulador da criminalidade juvenil, trazendo um desserviço à paz social.

$6 \quad$ A oficina com pesquisadores brasileiros foi estruturada com o propósito de estimular o apoio à pesquisa sobre o trabalho infantil no país. O evento deu origem ao edital que fomentou projetos de investigação, eventos e publicações em várias direções. Na ocasião, foram narradas experiências de combate ao trabalho precoce financiadas pelo programa IPEC da OIT e pesquisas em áreas críticas de vários estados, com ênfase no trabalho da cana de açúcar, carvoarias, olarias e algumas atividades tipicamente urbanas. Os grupos de trabalho discutiram por 2 dias os vários pontos a serem contemplados numa estratégia abrangente de pesquisa e intervenção tendo como referência os dados e estimativas levantados pelo Ministério do Trabalho para as várias regiões e estados brasileiros.

7 Apoiaram e participaram os Ministérios do Trabalho, Saúde e Educação, a OIT, o UNICEF, a Organização Panamericana da Saúde e as agências governamentais CAPES e CNPq, num ensaio imponente de articulaçãointerinstitucional.

8 Em tese de doutoramento recentemente defendida, Campos (2001) defende o valor da visão marxiana do trabalho explorado no capitalismo, onde o trabalho infantil constitui-se como um elo importante no processo global de exploração.

9 Um exemplo claro é o da inserção maciça de crianças e adolescentes no trabalho doméstico e na lavoura fumageira na região do Vale do Rio Pardo, no Rio Grande do Sul, um dos maiores pólos produtores mundiais. A pobreza não compõe um elemento explicativo dessa inserção. Além dos fatores de natureza cultural e ideológica, as raízes econômicas são de outra ordem, entre elas a relação de subordinação dos pequenos produtores familiares com os monopólios industriais transnacionais, "que define um vínculo econômico e moral" (Cf. Hoelzel, 2000). A cultura do fumo no Brasil exige mão de obra intensiva num ciclo que dura cerca de 10 meses, sendo imperativo o envolvimento do grupo familiar.

10 Ferreira (1999). Foram estudadas as áreas produtivas de cítricos (Boquim-Sergipe), fumageira, de Arapiraca-Alagoas, casas de farinha em Lagoa Nova e ten. Laurentino Cruz e tecelagens, em Jardim de Piranhas, todos no Rio Grande do Norte.

11 Embora tenha sido encontrada uma criança de quatro anos na amostra.

12 O fato de perceber o trabalho infantil como uma prática ilegal traduz-se numa postura do sistema de saúde que desconhece essa clientela, na medida em que conhecê-la melhor e orientar recursos e propostas de atenção a ela poderia implicar uma forma de legitimação de tal prática. Essa discussão existe, mas não consegue avançar, principalmente se levarmos em conta a disseminação do trabalho infantil e suas consequiências para a saúde de crianças e adolescentes. Deixa-se assim de construir - junto com outros setores de políticas - uma rede consistente de encaminhamentos e tentativas de soluções para um contingente enorme desses trabalhadores. 
Marcos Artemio Fischborn Ferreira, doutor em Saúde Coletiva pela Universidade de Campinas, é professor do Programa de Pós-Graduação em Desenvolvimento Regional da Universidade de Santa Cruz do Sul-UNISC (RS). Endereço para correspondência: Av. Independência, 2293, 96815-900, Santa Cruz do Sul, RS. Fone/fax: (51)717-7392.E-mail: marcospoa@uol.com.br. 